\title{
The Importance of Metallographic Etching for Failure Analysis of Metals
}

\author{
Frauke Hogue
}

Hogue Metallography, Pacific Palisades, CA 90272

Metallography is one of the tools of failure analysis that is often overlooked or ignored because it is a very basic technique that does not require expensive and sophisticated equipment. But in order to find good and reliable results, an experienced technician is required. This presentation is giving some examples how metallographic etching and light microscopy can be used to answer specific questions in failure analysis.

440A martensitic stainless steel dies failed in fatigue after a short time. SEM examination did not show a specific defect at the failure origin. Metallographic mounts were made of the failed part and a good part for comparison. After etching with Kalling's reagent (Fig. 1a), a common etchant for stainless steels, a slight difference in structure between the two samples was visible. Experimentation with several etchants revealed a needle like phase when etched with Fry's reagent (Fig.1b). Re-austentizing, quenching and tempering removed that phase, identifiying it as cementite. The re-heat treated parts performed well.

The degtree of spheroidization of the cementite particles in a steel containing $1.3 \% \mathrm{C}$ had to be determined. Image analysis is generally utilized for this process. Etching the sample with nital (Fig. 2a) also reveals the ferrite grainboundaries, which look like long cementite partlicles to the computer. Using picral only outlines the cementite (Fig. 2b) facilitating the use of automatic image analysis.

The delta ferrite content in a 15-5 PH stainless steel casting was to be determined with image analysis. Etching the metallographic sample with Kalling's reagent reveals the martensitic structure and also delta ferrite (Fig. 3a), but image analysis would not be able to select the areas of delta for calculation. Using an electrolytic etch with a $10 \% \mathrm{KOH}$ solution only the delta ferrite is colored (Fig. 3b), facilitating automatic image analysis.

A super duplex stainless steel casting failed in service. Exposure to temperatures causing formation of embritteling sigma phase was suspected. Many different etchants have been reported in publications including Murakami's reagent. Because of environmental concerns I like to use the mildest etchants possible. Experiments were peformed with electrolytic $\mathrm{KOH}, \mathrm{NaOH}$ and oxalic etchants. All three etchants were able to differentiatr austenite, delta ferrite and sigma phase. But in some instances following the reported parameters caused over-etching and dissolution of some phases. In order to achieve results where all phases are readily identifiable, the parameters have to be changed form the reported values. Experimentation is essential and it is recommended to start with low voltages and short etching times.

Standard 10\% oxalic acid in water at $3 \mathrm{~V} \mathrm{DC}$ for $25 \mathrm{sec}$ was used for Fig 4a. Austenite is white, delta light grey, sigma attacked. 10n KOH was used for Fug 4b at 2V DC for $15 \mathrm{sec}$. Austenite is white, delta brown, and sigma brown and attacked.

More examples will discussed in the presentation. 


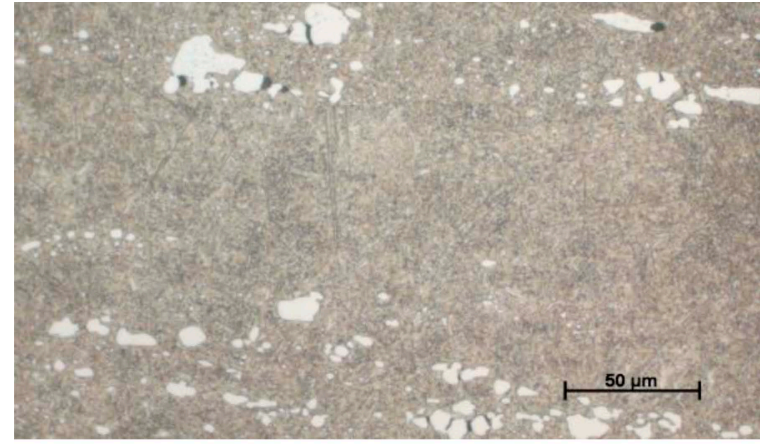

Fig. 1 440A SS a - Kalling's Etch

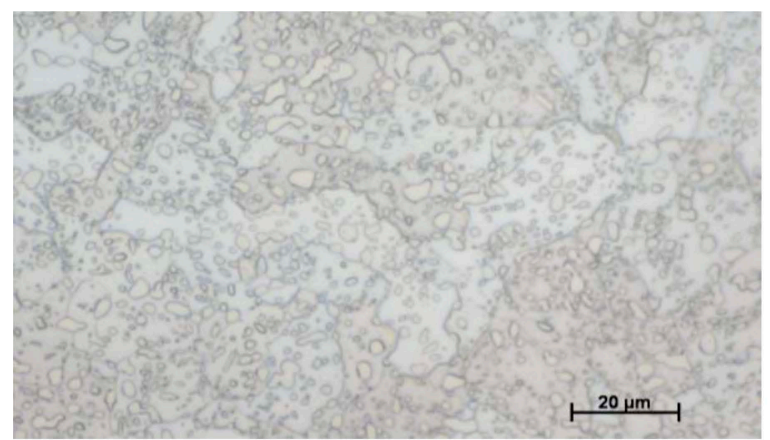

Fig. 2 Spheroidized Structure a - Nital Etch

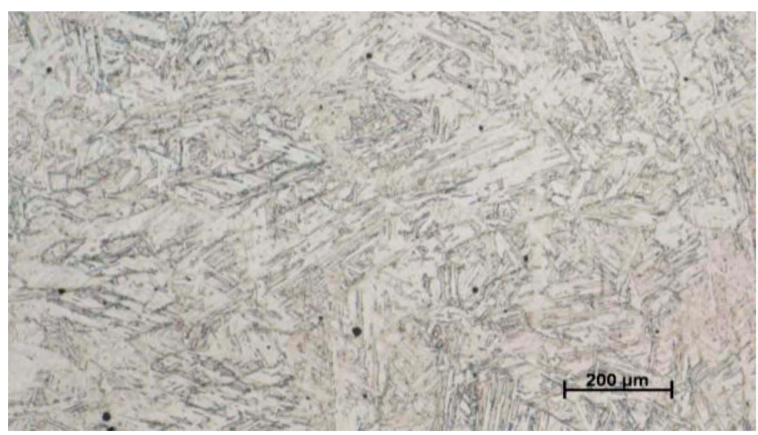

Fig. 3 15-5 PH SS

a - Kalling's Etch

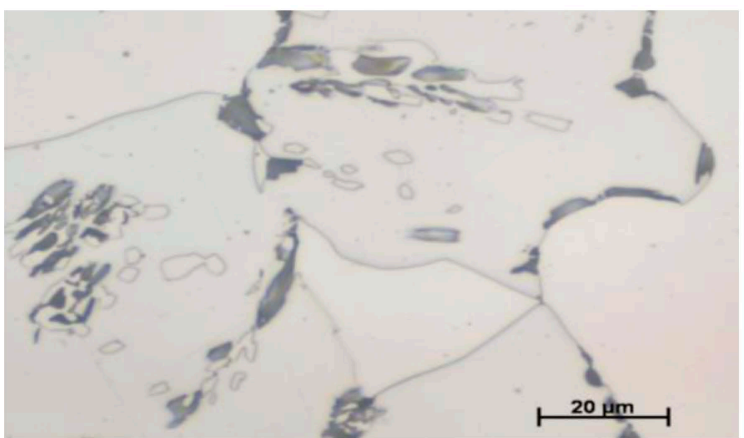

Fig. 4 Duplex SS a -Electrolytic Oxalic Etch
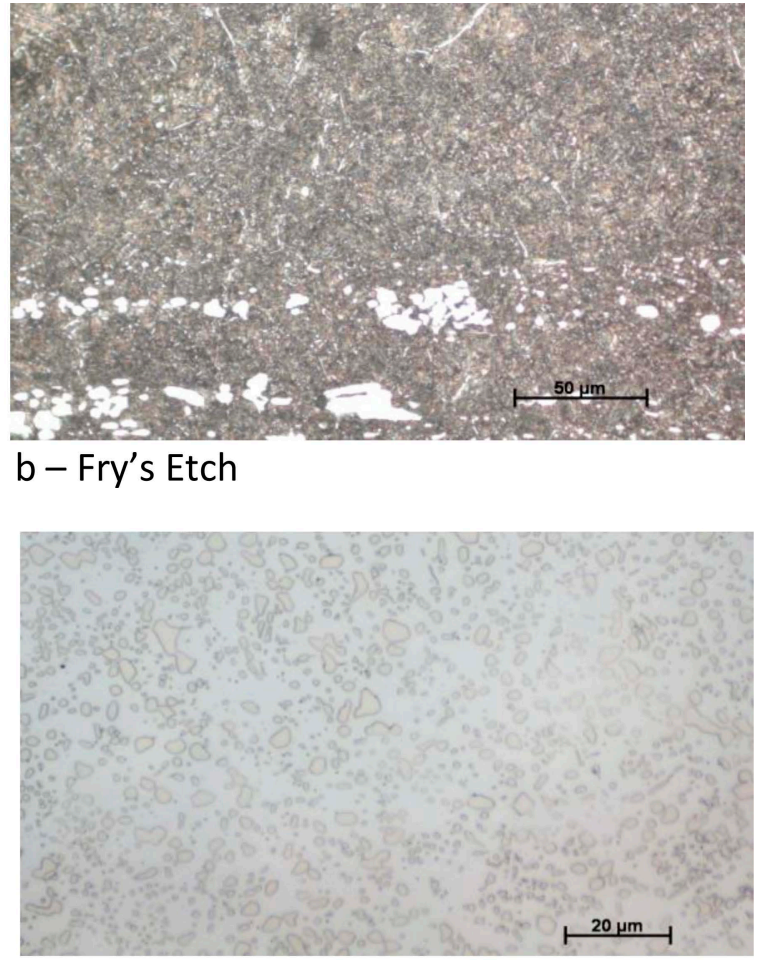

b - Picral Etch

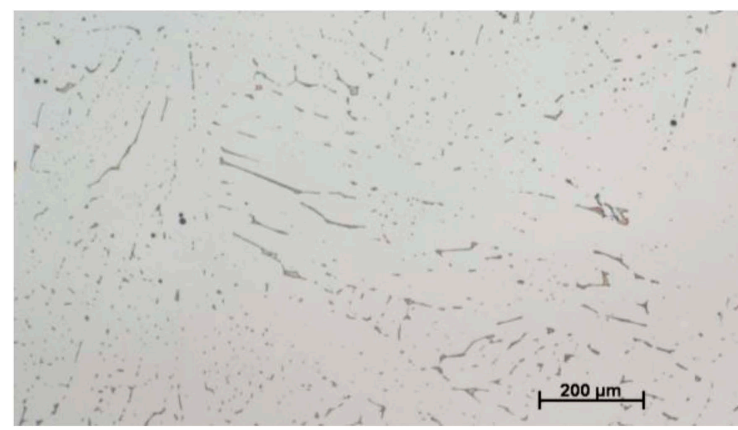

b - Electrolytic $\mathrm{KOH}$ Etch

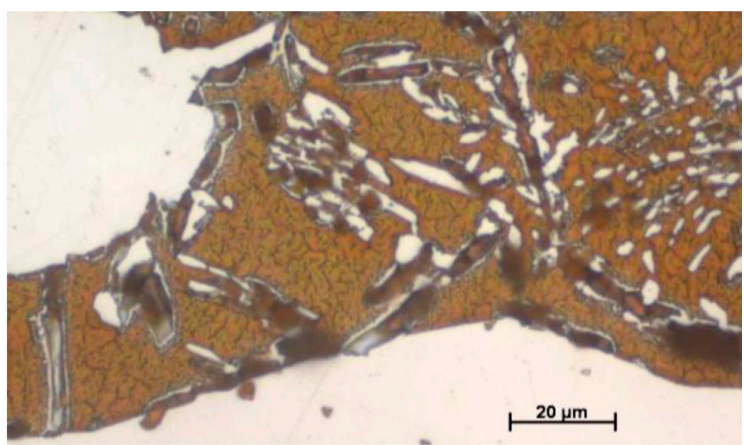

b - Electrolytic KOH Etch 